\title{
Clinical characteristics, disease activity, functional status, and quality of life results of patients with psoriatic arthritis using biological and conventional synthetic disease-modifying antirheumatic drugs
}

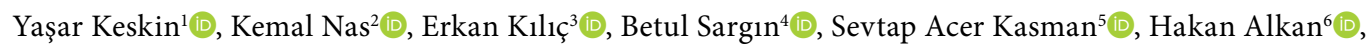

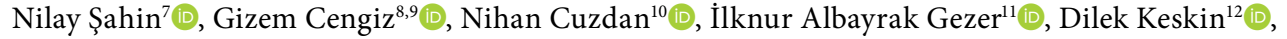

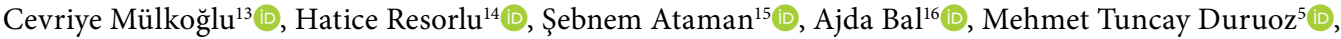

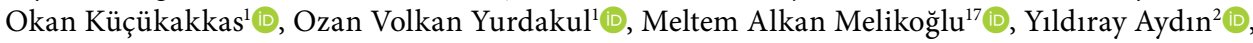

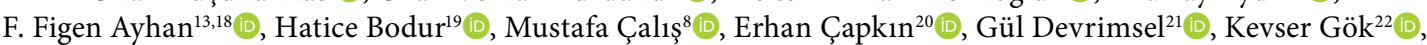

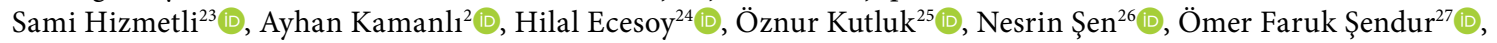

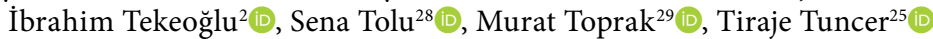

${ }^{1}$ Department of Physical Medicine and Rehabilitation, Bezmiâlem Foundation University, Istanbul, Turkey ${ }^{2}$ Department of Physical Medicine and Rehabilitation, Division of Rheumatology and Immunology, Sakarya University School of Medicine, Sakarya, Turkey ${ }^{3}$ Department of Physical Medicine and Rehabilitation, Rheumatology Clinic, Kanuni Training and Research Hospital, Trabzon, Turkey ${ }^{4}$ Department of Physical Medicine and Rehabilitation, Division of Rheumatology, Adnan Menderes University School of Medicine, Aydin, Turkey ${ }^{5}$ Department of Physical Medicine and Rehabilitation, Division of Rheumatology, Marmara University School of Medicine, Istanbul, Turkey

${ }^{6}$ Department of Physical Medicine and Rehabilitation, Pamukkale University School of Medicine, Denizli, Turkey

${ }^{7}$ Department of Physical Medicine and Rehabilitation, Ballkesir University School of Medicine, Balikesir, Turkey

${ }^{8}$ Department of Physical Medicine and Rehabilitation, Division of Rheumatology, Erciyes University School of Medicine, Kayseri, Turkey

${ }^{9}$ Department of Physical Medicine and Rehabilitation, Rheumatology Clinic, Van Training and Research Hospital, Van, Turkey

${ }^{10}$ Department of Physical Medicine and Rehabilitation, Rheumatology Clinic, Şanluurfa Training and Research Hospital, Şanlıurfa, Turkey

${ }^{11}$ Department of Physical Medicine and Rehabilitation, Selçuk University School of Medicine, Konya, Turkey

${ }^{12}$ Department of Physical Medicine and Rehabilitation, Kirıkkale University School of Medicine, Kirıkkale, Turkey

${ }^{13}$ Department of Physical Medicine and Rehabilitation, Ankara Training and Research Hospital, Ankara, Turkey

${ }^{14}$ Department of Physical Medicine and Rehabilitation, Çanakkale Onsekiz Mart University School of Medicine, Çanakkale, Turkey ${ }^{15}$ Department of Physical Medicine and Rehabilitation, Division of Rheumatology, Ankara University School of Medicine, Ankara, Turkey

${ }^{16}$ Department of Physical Medicine and Rehabilitation, Dışkapı Yıldırım Beyazıt Training and Research Hospital, Ankara, Turkey

${ }^{17}$ Department of Physical Medicine and Rehabilitation, Division of Rheumatology, Atatürk University School of Medicine, Erzurum, Turkey

${ }^{18}$ Department of Physical Medicine and Rehabilitation, Uşak University, High School of Health Sciences, Uşak, Turkey

${ }^{19}$ Department of Physical Medicine and Rehabilitation, Yıldirım Beyazıt university School of Medicine, Ankara, Turkey

${ }^{20}$ Department of Physical Medicine and Rehabilitation, Karadeniz Technical University School of Medicine, Trabzon, Turkey

${ }^{21}$ Department of Physical Medicine and Rehabilitation, Recep Tayyip Erdoğan University School of Medicine, Rize, Turkey

${ }^{22}$ Department of Physical Medicine and Rehabilitation, Ankara Numune Training and Research Hospital, Ankara, Turkey

${ }^{23}$ Department of Physical Medicine and Rehabilitation, Division of Rheumatology, Cumhuriyet University School of Medicine, Sivas, Turkey ${ }^{24}$ Department of Physical Medicine and Rehabilitation, Division of Rheumatology, Necmettin Erbakan University Meram School of Medicine, Konya, Turkey

${ }^{25}$ Department of Physical Medicine and Rehabilitation, Division of Rheumatology, Akdeniz University School of Medicine, Antalya, Turkey

${ }^{26}$ Department of Physical Medicine and Rehabilitation, Rheumatology Clinic, Kartal Dr. Lütfi Kirdar Training and Research Hospital, Istanbul, Turkey

${ }^{27}$ Department of Physical Medicine and Rehabilitation, Adnan Menderes University School of Medicine, Aydin, Turkey

${ }^{28}$ Department of Physical Medicine and Rehabilitation, Medipol University School of Medicine, Istanbul, Turkey

${ }^{29}$ Department of Physical Medicine and Rehabilitation, Yüzüncü Yıl University School of Medicine, Van, Turkey

Received: November 07, 2019 Accepted: January 24, 2020 Published online: July 01, 2020

Correspondence: Yaşar Keskin, MD. Bezmiâlem Vakıf Üniversitesi Tıp Fakültesi Hastanesi, Fiziksel Tıp ve Rehabilitasyon Anabilim Dalı, 34093 Fatih, İstanbul, Türkiye. Tel: +90 212 - 5232288 e-mail: ykeskin42@hotmail.com

\section{Citation:}

Keskin Y, Nas K, Kılıç E, Sargın B, Acer Kasman S, Alkan H, et al. Clinical characteristics, disease activity, functional status, and quality of life results of patients with psoriatic arthritis using biological and conventional synthetic disease-modifying antirheumatic drugs. Arch Rheumatol 2021;36(1):1-9.

This is an open access article under the terms of the Creative Commons Attribution-NonCommercial License. which permits use. distribution and reproduction in any medium. provided the original work is properly cited and is not used for commercial purposes (http://creativecommons.org/licenses/by-nc/4.0/). 


\begin{abstract}
Objectives: This study aims to compare the clinical characteristics, disease activity, and quality of life (QoL) of patients with psoriatic arthritis (PsA) who use biological and conventional synthetic disease-modifying antirheumatic drugs (DMARDs) in a nationwide cohort throughout Turkey.

Patients and methods: A total of 961 patients ( 346 males, 615 females; mean age: $46.9 \pm 12.2$ years; range, 18 to 81 years) with PsA according to the classification criteria for PsA were included in the study. The patients' demographic and clinical characteristics, physical examination results, Disease Activity Score 28, Disease Activity Index for Psoriatic Arthritis and Bath Ankylosing Spondylitis Disease Activity Index (BASDAI), Psoriasis Area and Severity Index, Bath Ankylosing Spondylitis Functional Index, Bath Ankylosing Spondylitis Metrology Index, Hospital Anxiety and Depression Scale, Health Assessment Questionnaire, Psoriatic Arthritis Quality of Life (PsAQoL), and Short Form-36 scores were all recorded.

Results: Of the patients, $23 \%$ underwent biological DMARD (bDMARD) monotherapy, 42\% underwent conventional synthetic DMARD (csDMARD) monotherapy, $10 \%$ underwent a csDMARD combination therapy, and 10\% underwent a combination bDMARD and csDMARD treatment. The Visual Analog Scale (VAS pain), patient global assessment, physician global assessment, and BASDAI scores were found to be lower among patients using combination treatment of csDMARD and bDMARD, while the swollen joint count was found to be lower among patients using bDMARD. The PsAQoL score was found to be the lowest among patients not using any medication and the highest among those using bDMARD.

Conclusion: In our study, patients with PsA were successfully treated with both csDMARD and bDMARD monotherapy. When the biological treatments used for PsA were compared with csDMARD, it was found that biological treatments had a positive effect on both disease activity and the QoL. Combinations of csDMARDs and bDMARDs were preferred in cases in which the disease activity was still high or increased. Because of the highest efficacy of the combined treatment, we highly suggest increasing the number of patients on combined treatment.

Keywords: Disease-modifying antirheumatic drug, functional status, psoriatic arthritis, quality of life.
\end{abstract}

Psoriatic arthritis (PsA) is an inflammatory disease that can affect the peripheral joints, axial skeleton, skin, and nails. The disease is part of the spondyloarthritis group and related to psoriasis. ${ }^{1}$

Psoriatic arthritis is a heterogeneous disease that can vary from a mild disease state to an erosive and deformative state. ${ }^{2}$ If left untreated, it can cause progressive joint damage, disability, disruption of functional status, decreased quality of life (QoL), and significantly increased mortality. ${ }^{3-5}$ Disability and increased mortality in PsA can be associated with both inflammatory skin lesions and joint damage.

Conditions such as disability, decreased physical activity, long-term comorbidities, and increased anxiety and depression during PsA further increase the burden of the disease. ${ }^{6,7}$ Early diagnosis and adequate treatment methods may help in avoiding such complications. ${ }^{8}$

According to the European League Against Rheumatism (EULAR) and Group for Research and Assessment of Psoriasis and Psoriatic Arthritis (GRAPPA) treatment guidelines, there are multiple treatment options available for PsA. The treatment is designed based on disease severity and disease activity. Treatment options include pharmacological and non-pharmacological strategies. ${ }^{9} \quad$ Non-pharmacological strategies include patient training, exercise, and weight loss along with physical, occupational, and psychological therapies. In mild-to-medium disease activity, the disease is treated with conventional synthetic disease-modifying antirheumatic drugs
(csDMARDs) and non-steroidal anti-inflammatory drugs (NSAIDs). If this treatment is not effective or if intolerance and side effects emerge, biological DMARDs (bDMARDs) can be added to the treatment regime. ${ }^{10}$ The objective is to control the symptoms and inflammation, prevent progressive structural damage, and increase the QoL of the patients as much as possible by aiming for clinical remission through appropriate treatment options. ${ }^{11}$ In this study, we aimed to compare the clinical characteristics, disease activity, and QoL of patients with PsA who use biological and conventional synthetic DMARDs in a nationwide cohort throughout Turkey.

\section{PATIENTS AND METHODS}

This cross-sectional study was conducted between February and December in 2018. The study included the demographic characteristics and clinical and laboratory data of 961 PsA patients (346 males, 615 females; mean age: $46.9 \pm 12.2$ years; range, 18 to 81 years) who were treated as part of their routine examinations. The clinical data obtained during the routine clinic visits of the patients were added to the electronic forms by using a national network that also serves as a scientific research cooperation platform (https://www.trasd-network.org). Patients with PsA from 25 different centers (University as well as Training and Research Hospitals) in Turkey who met the classification criteria for PsA, were undergoing csDMARD and bDMARD monotherapy or a combination treatment, aged 
above 18 years, and had no other rheumatic disease(s) were included in the study. Patients who were diagnosed with psoriasis by dermatologists but who did not have arthritis, female patients who were pregnant or breastfeeding and patients with malignancies were excluded. The study protocol was approved by the Sakarya University Faculty of Medicine Ethics Committee (Approval date/no: 25.01.2018/42). A written informed consent was obtained from each patient. The study was conducted in accordance with the principles of the Declaration of Helsinki.

Patients were divided into four groups according to the given treatment as those who were not using any medication, those who received csDMARD monotherapy, those who received bDMARD monotherapy, and those under combination bDMARD and csDMARD therapy.

Patients' demographic characteristics (sex and age), body mass index (BMI), age at the onset of psoriasis (years), age at the onset of PsA (years), duration of psoriasis (years), duration of PsA (years), delay in PsA diagnosis (years), patient global assessment (PtGA), and physician global assessment (PhGA) were recorded.

Tender joint count and swollen joint count (SJC) of the patients were checked during the examination. The pain of the patients was evaluated using the Visual Analog Scale (VAS-pain).

Disease activity of the patients was evaluated using the Disease Activity Score 28 (DAS28), Disease Activity Index for Psoriatic Arthritis (DAPSA), and the Bath Ankylosing Spondylitis Disease Activity Index (BASDAI). ${ }^{12,13}$ Psoriasis severity was evaluated using the Psoriasis Area and Severity Index, ${ }^{14}$ and the functional status was evaluated using the Bath Ankylosing Spondylitis Functional Index, ${ }^{15}$ and the Bath Ankylosing Spondylitis Metrology Index. ${ }^{16}$ The risk of anxiety and depression was evaluated using the Hospital Anxiety and Depression Scale, and the QoL was evaluated using the Health Assessment Questionnaire (HAQ), ${ }^{17}$ Psoriatic Arthritis Quality of Life (PsAQoL), ${ }^{18}$ and the short form (SF)-36. ${ }^{19}$

\section{Statistical analysis}

Statistical analyses were performed using the IBM SPSS for Windows version 22.0 software (IBM Corp., Armonk, NY, USA). Whether the continuous numerical variables were normally distributed was evaluated using the Shapiro-Wilk test. Results of the numerical variables were presented as mean \pm standard deviation (SD). Because the comparisons between the groups did not show a normal distribution, non-parametric tests were used. To compare the data for determining the level of significance between the groups, Kruskal-Wallis test was used for continuous variables, while the chi-square test or Fisher's exact test was used for the categorical variables. In all statistical analyses, the level of significance was considered as $\mathrm{p}<0.05$.

\section{RESULTS}

The study included patients with complete treatment data constituted using the TRASD-network. Of these patients, 36\% were males and 547 (57\%) were active smokers. Mean BMI was 28.4 (17.7-53.3) kg/m², and average duration of symptoms was seven years (range, 0 to 59 years). Hip pain, peripheral arthritis, spondylitis, and inflammatory back pain were identified in 211 (22\%), 430 (45\%), 351 (37\%), and $430(45 \%)$ of the patients, respectively.

There was no difference between the groups with regards to active smoking rates. The incidence of chronic back pain (50\%) and morning stiffness in spine (49\%) was high among the patients not using any medication, while that of spondylitis (47\%), inflammatory back pain (57\%), and enthesopathy (48\%) was high among patients using bDMARD. The incidence of peripheral arthritis (73\%) was the highest among patients using csDMARD. While the time span for delay in diagnosis of PSA was similar between the groups, the duration of symptoms (10 years; range, 1 to 49 years) and the duration since PsA diagnosis (7 years; range, 1 to 39 years) were determined to be the highest in the group using a combination of csDMARD and bDMARD and the lowest in the group not using any medication (5 years; range, 0 to 42 years and 2 years; range, 0 to 41 years, respectively) (Table 1).

Of the patients, 221 (23\%) underwent bDMARD monotherapy (adalimumab: 73, etanercept: 49, infliximab: 35, golimumab: 22, certolizumab pegol: 26, ustekinumab: 10 , and secukinumab: 6); 407 (42\%) underwent csDMARD monotherapy 


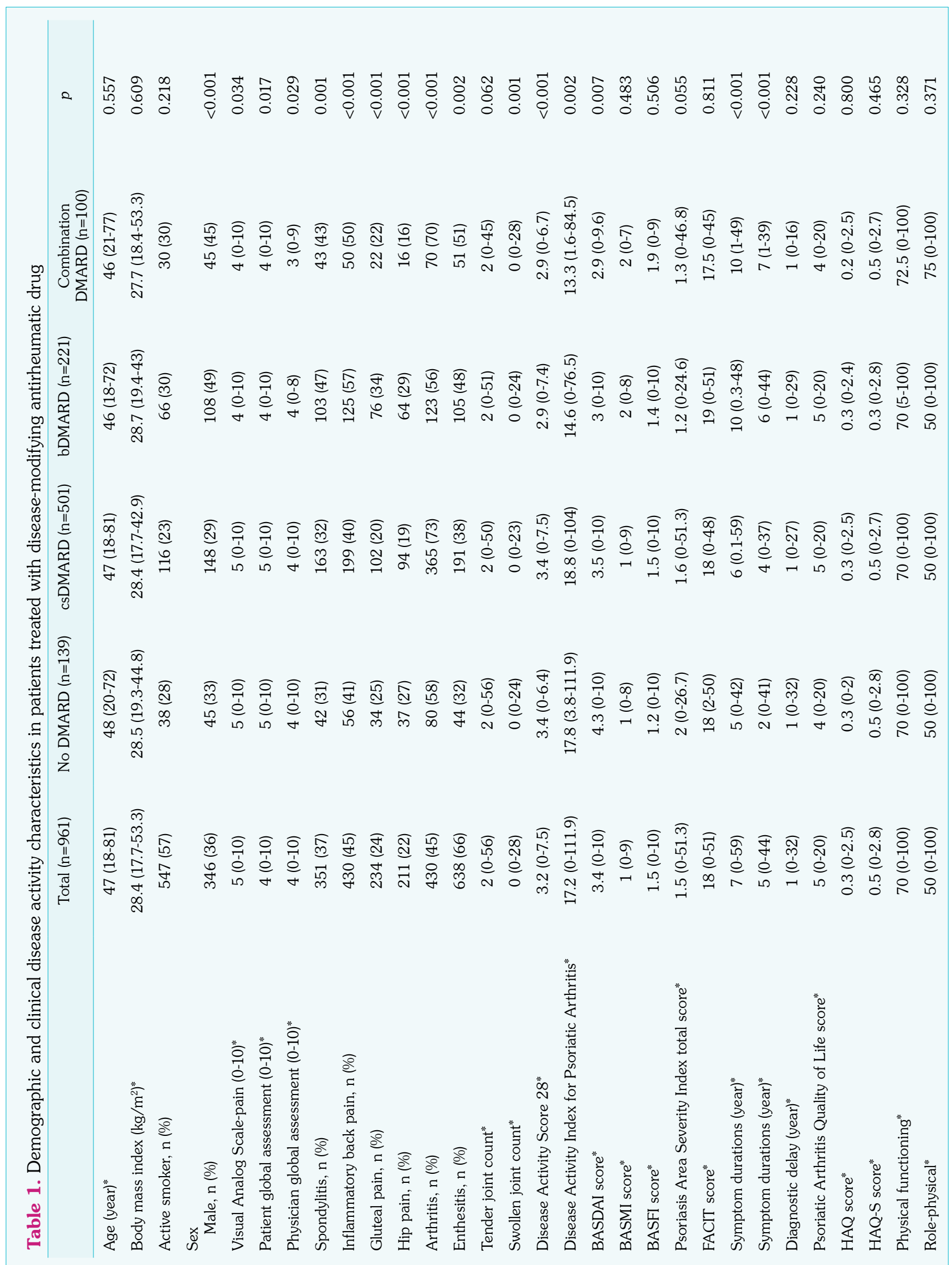




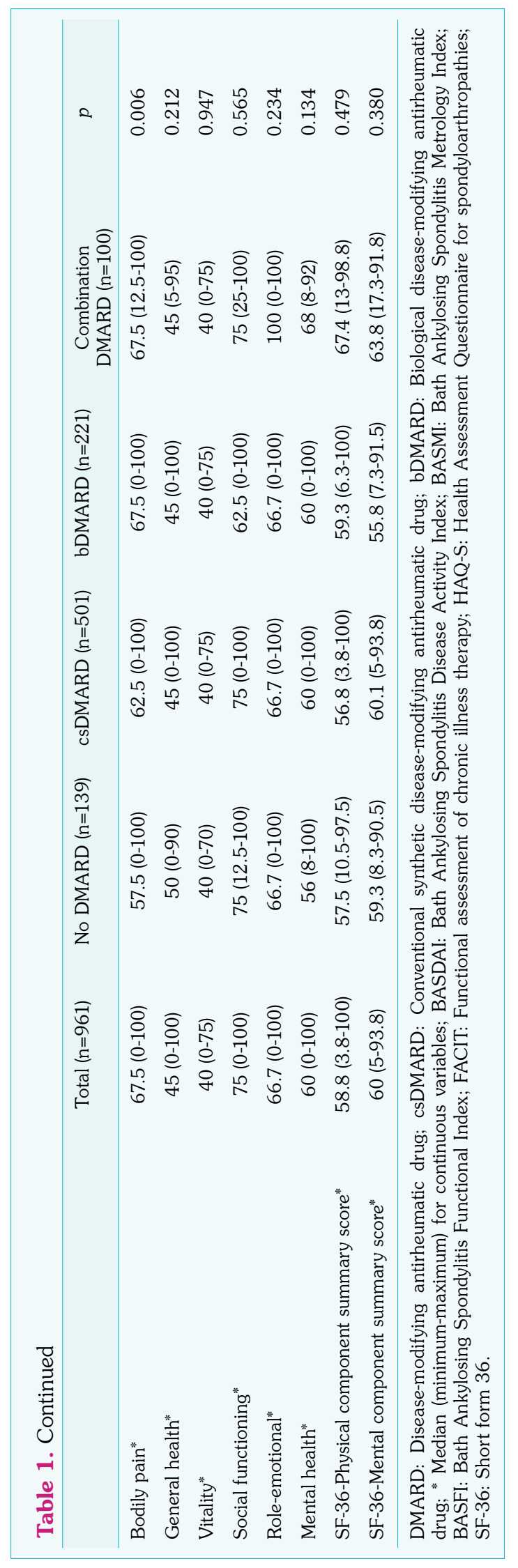

\begin{tabular}{|lcc|}
\hline \multicolumn{3}{|l|}{ Table 2. Psoriatic arthritis treatment regimen at clinic } \\
visit $(\mathrm{n}=961)$ & $\mathrm{n}$ & $\%$ \\
\hline Treatment & 407 & 42 \\
\hline Monotherapy with any csDMARD & 295 & 31 \\
Methotrexate & 62 & 6 \\
Sulfasalazine & 42 & 4 \\
Leflunomide & 4 & 0.4 \\
Hydroxychloroquine & 4 & 0.4 \\
Cyclosporine & 94 & 10 \\
Combination with one or more csDMARD & 221 & 23 \\
Monotherapy with any bDMARD & 73 & 8 \\
Adalimumab & 49 & 5 \\
Etanercept & 35 & 4 \\
Infliximab & 22 & 2 \\
Golimumab & 26 & 3 \\
Certolizumab pegol & 10 & 1 \\
Ustekinumab & 6 & 1 \\
Secukinumab & 100 & 10 \\
Combination bDMARD with one or more & & \\
csDMARD & & \\
\hline csDMARD: Conventional synthetic disease-modifying antirheumatic drug; \\
bDMARD: Biological disease-modifying antirheumatic drug. \\
\end{tabular}

(methotrexate [MTX]: 295; Sulfasalazine [SSZ]: 62, and others: 50), and 94 (10\%) underwent csDMARD combination treatment. In addition, 100 (10\%) patients with PsA who underwent bDMARD treatment were administered a combination therapy with any csDMARD as well. It was found that $137(14 \%)$ of the patients did not undergo any DMARD treatment (Table 2).

Notably, the VAS-pain, PtGA, PhGA, SJC, and BASDAI scores were the highest in the group not using any medication (5, range, 0 to $10 ; 5$, range, 0 to $10 ; 4$, range, 0 to $10 ; 0$, range, 0 to 24; and 4.3, range, 0 to 10 , respectively), while the VAS-pain, PtGA, PhGA, and BASDAI scores were the lowest in the combination csDMARD and bDMARD group (4, range, 0 to $10 ; 4$, range, 0 to $10 ; 3$, range, 0 to 9 ; and 2.9 , range, 0 to 9.6, respectively). The SJC was the lowest in the bDMARD group ( 3 , range, 0 to 10). DAS28 score was the highest in the group not using any medication (3.2, range, 0 to 7.5 ) and lowest in both groups using bDMARD (2.9, range, 0 to 7.4) and combination of csDMARD and bDMARD (2.9, range, 0 to 6.7). The DAPSA score was the highest in the group not using any medication (17.2, range, 0 to 111.9 ) and the lowest in 
csDMARD and bDMARD combination group (13.3, range, 1.6 to 84.5) (Table 1).

Evaluation of the QoL in the groups revealed that the PsAQoL score was the lowest (5, range, 0 to 20 ) in the group not using any medication and the highest (5, range, 0 to 20 ) in the group using bDMARD. SF-36 physical component score (PCS) was the highest in the combination csDMARD and bDMARD group (67.4, range, 13 to 98.8) and the lowest in the group using csDMARD (56.8, range, 3.8 to 100$)$ and bDMARD (59.3, range, 6.3 to 100). SF-36 mental component scores (MCSs) were the highest in the combination csDMARD and bDMARD group (63.8, range, 17.3 to 91.8 ) and the lowest in the group using bDMARD (55.8, range, 7.3 to 91.5). However, there was no difference between the SF-36 PCSs and SF-36 MCSs. Interestingly, among the subscales of SF-36, the bodily pain subscale was found to be significantly the lowest in the combination csDMARD and bDMARD group (67.5, range, 12.5 to 100) and the group not using any medication (57.5, range, 0 to 100$)$ (Table 1 ).

\section{DISCUSSION}

This study evaluated the clinical characteristics, disease activity, and the QoL of patients in Turkey who used DMARD for PsA diseases. The rate of incidence of inflammatory backache (57\%) and enthesopathy (48\%) was higher among the patients using bDMARD, and the presence of peripheral arthritis (73\%) was higher among the patients using csDMARD. The VAS-pain, PtGA, PhGA, SJC, DAS28-erythrocyte sedimentation rate, and BASDAI scores were significantly higher among the patients not using any medication.

Recently published guidelines of the GRAPPA and EULAR recommend using bDMARD on active arthritis patients with inadequate response to NSAID and csDMARD. ${ }^{11}$ For patients with PsA, bDMARD has shown positive effects on the QoL by ensuring a significant improvement in physical functions. ${ }^{20}$

An overview of the treatment options used in our study reveals that most of the patients with PsA underwent csDMARD therapy, with csDMARD monotherapy being used the most (42\%). Among csDMARD users, the most commonly used treatment was that of MTX (31\%), and the least commonly used treatments were those of hydroxychloroquine $(0.4 \%)$ and ciclosporin (0.4\%). Reason for the low use of leflunomide, hydroxychloroquine, and cyclosporine in the treatment of PsA, according to the recommendations of GRAPPA and EULAR, it is may not be only a first-line treatment but also limited effectiveness in treatment. Among the patients, 23\% underwent bDMARD monotherapy. The most used bDMARD was adalimumab (8\%), while the least used ones were ustekinumab (1\%) and secukinumab (1\%). In our study, the reason why use of ustekinumab and secukinumab for the treatment of PsA was lower compared to other biological therapies may be due to the successful continuation of low disease activity because of the previously initiated biological therapies. In a multi-center study conducted in Australia that compared DMARD treatments $(n=2,948)$, clinical symptoms of disease in the majority of patients with PsA were kept under control using csDMARD monotherapy (46\%) and bDMARD monotherapy (19\%). ${ }^{21}$

As seen in previous studies, difficulties in early diagnosis can cause a prolonged treatment process and delay in initiating early treatment. Thus, patients diagnosed at a later age tend to experience more damage and higher disease activity. ${ }^{22}$ In a country-wide study in Denmark, the delay in diagnosis for patients with PsA was found to be 56 months (4.6 years). ${ }^{23}$ In this study, we determined that the delay in diagnosis for patients with PsA was 2.9 \pm 4.5 years. The average time between the onset of PsA and its diagnosis and the average duration of symptoms were $9.6 \pm 8.7$ and $6.7 \pm 7.1$ years, respectively, and these were significantly higher among patients using combination csDMARD and bDMARD (mean \pm SD: $11.5 \pm 8.2$ and $8.7 \pm 6.8$ years, respectively). This shows that as the beginning of treatment is delayed, there is greater need for biological treatment to regulate the disease activity. One of the reasons for the delay in diagnosis is the long-term follow-up of patients with psoriasis before establishing the diagnosis of PsA and focusing more on skin findings.

The DAPSA is a useful instrument that enables the assessment of the treatment response level and disease activity in PsA. ${ }^{13,24}$ In the literature, a study using DAPSA and clinical DAPSA for 
evaluating disease activity determined that while the disease activity was moderate among patients undergoing csDMARD monotherapy and combination, the average disease activity was in the "remission" stage among those undergoing a combination csDMARD and bDMARD therapy or a bDMARD monotherapy. ${ }^{25,26}$ In agreement with these findings, our study determined that the average disease activity among patients not using any medication and those undergoing csDMARD monotherapy was higher compared with that of patients undergoing combination csDMARD and bDMARD therapy or a bDMARD monotherapy. Similarly, according to the DAS28 criteria, it was observed that most patients were kept under control superiorly with bDMARD monotherapy or any combination with csDMARD. This shows that bDMARDs are effective in suppressing the parameters associated with disease activity. ${ }^{27}$

Presence of enthesitis is known to cause increased morbidity by causing erosion in the joints of patients with PsA. ${ }^{28}$ In this study, we determined that most of the patients had enthesitis (66\%). Our study had a higher prevalence of enthesitis compared with previously conducted studies. ${ }^{29,30}$ While it was significantly higher among the patients using combination DMARDs (51\%), the prevalence of enthesitis was the lowest in those not using any medication. This shows that bDMARDs are required to suppress enthesitis and disease activity in patients with PsA, by the addition of bDMARD to csDMARD. Previous studies report that while NSAIDs and csDMARDs are the first option in the treatment of enthesitis, their effects are limited. In contrast, there is evidence that bDMARDs are effective in the treatment of enthesitis in PsA. ${ }^{31-34}$

Because of the heterogeneity and complexity of PsA, it is difficult to clinically evaluate the patients. Patients with PsA experience functional impairment and lower QoL, which is why global evaluation of patients with PsA essentially involves a description of both the physical and psychological aspects. ${ }^{35,36}$ In agreement with the previously performed studies, we obtained lower scores among patients who used combination csDMARD and bDMARD in the physician and patient global evaluations. ${ }^{37}$

Our analysis showed that patients with PsA have lower SF-36 physical and mental scores and lower health-related QoL scores compared with the general population. ${ }^{38}$ In a study conducted by Gottlieb et al., ${ }^{39}$ SF-36 PCSs in patients with PsA were similar to the ones reported in the literature, while the SF-36 MCSs were lower. In a study conducted in the general population in Norway, a comparison of patients with PsA using bDMARD with those using csDMARD revealed that the scores for the bodily pain, vitality, physical role, and general health perception subscales of SF-36 showed greater improvement. ${ }^{40}$ In this study, we did not find any significant difference between the SF-36 PCSs and MCSs. However, the score for the general bodily pain subscale of SF-36 was the highest among the patients using combination cDMARDs and bDMARDs and the lowest among those not using any medication.

The HAQ is a questionnaire that evaluates the functionality of patients based on their pain and ability to perform daily life activities. ${ }^{41}$ HAQ for the spondyloarthropathies (HAQ-S) is a questionnaire developed specifically for individuals with spondyloarthropathies. ${ }^{42}$ Recent studies show that the treatments performed with different agents ensure the improvement of rheumatic symptoms in patients with PsA. When biological treatments were compared with csDMARDs in patients with PsA, the HAQ scores were found to be significantly lower. ${ }^{43}$ However, in our study, no significant difference was observed in the DMARDs in terms of their associated HAQ and HAQ-S scores. ${ }^{44}$

Limitations of our study included the fact that it was a cross-sectional, observational study, meaning that the present data included the evaluation of the disease for only a certain period in patients with a prolonged disease state. For this reason, the factors that affected the results of the study may have not been fully identified. Another limitation was that this study included patients using csDMARD and bDMARD and represented a majority of PsA cases. However, patients who needed to use NSAID and corticosteroids are monitored as part of general practice and may be included into the treatment program for only a brief period, which is why they were not included in the study. The strengths of this study included the fact that it is a multi-center study covering all regions of Turkey and that it included a large database of patients. It also provided the opportunity to examine the relevant clinical 
characteristics and QoL between the patients who used DMARDs and those who did not use any medication.

In conclusion, in our study, patients with PsA were successfully treated with both csDMARD and bDMARD monotherapy. Both treatments have lowered the disease activity and positively influenced the QoL in patients with PsA. Combinations of csDMARDs and bDMARDs were preferred in cases in which the disease activity was still high or increased. Because of the highest efficacy of the combined treatment, we highly suggest increasing the number of patients on combined treatment.

\section{Disclaimer}

This disclaimer informs readers that the views, thoughts, and opinions expressed in the text belong solely to the author, and not necessarily to the author's employer, organization, committee or other group or individual or previous related publications.

\section{Declaration of conflicting interests}

The authors declared no conflicts of interest with respect to the authorship and/or publication of this article.

\section{Funding}

The authors received no financial support for the research and/or authorship of this article.

\section{REFERENCES}

1. Kruithof E, Baeten D, De Rycke L, Vandooren B, Foell $\mathrm{D}$, Roth $\mathrm{J}$, et al. Synovial histopathology of psoriatic arthritis, both oligo- and polyarticular, resembles spondyloarthropathy more than it does rheumatoid arthritis. Arthritis Res Ther 2005;7:R569-80.

2. Mease PJ, Gladman DD, Papp KA, Khraishi MM, Thaçi $\mathrm{D}$, Behrens F, et al. Prevalence of rheumatologistdiagnosed psoriatic arthritis in patients with psoriasis in European/North American dermatology clinics. J Am Acad Dermatol 2013;69:729-35.

3. Boehncke WH, Menter A. Burden of disease: psoriasis and psoriatic arthritis. Am J Clin Dermatol 2013;14:37788.

4. Strand V, Sharp V, Koenig AS, Park G, Shi Y, Wang $\mathrm{B}$, et al. Comparison of health-related quality of life in rheumatoid arthritis, psoriatic arthritis and psoriasis and effects of etanercept treatment. Ann Rheum Dis 2012;71:1143-50.

5. Husted JA, Tom BD, Farewell VT, Schentag CT, Gladman DD. Description and prediction of physical functional disability in psoriatic arthritis: a longitudinal analysis using a Markov model approach. Arthritis Rheum 2005;53:404-9.

6. Minnock P, Kirwan J, Veale D, Fitzgerald O, Bresnihan $B$. Fatigue is an independent outcome measure and is sensitive to change in patients with psoriatic arthritis. Clin Exp Rheumatol 2010;28:401-4.

7. Ogdie A, Schwartzman S, Eder L, Maharaj AB, Zisman D, Raychaudhuri SP, et al. Comprehensive treatment of psoriatic arthritis: managing comorbidities and extraarticular manifestations. J Rheumatol 2014;41:2315-22.

8. McLaughlin M, Ostör A. Early treatment of psoriatic arthritis improves prognosis. Practitioner 2014;258:21-4, 3.

9. Gossec L, Smolen JS, Ramiro S, de Wit M, Cutolo M, Dougados M, et al. European League Against Rheumatism (EULAR) recommendations for the management of psoriatic arthritis with pharmacological therapies: 2015 update. Ann Rheum Dis 2016;75:499-510.

10. Braun J, van den Berg R, Baraliakos X, Boehm H, Burgos-Vargas R, Collantes-Estevez E, et al. 2010 update of the ASAS/EULAR recommendations for the management of ankylosing spondylitis. Ann Rheum Dis 2011;70:896-904.

11. Coates LC, Gossec L, Ramiro S, Mease P, van der Heijde D, Smolen JS, et al. New GRAPPA and EULAR recommendations for the management of psoriatic arthritis. Rheumatology 2017;56:1251-3.

12. Garrett S, Jenkinson T, Kennedy LG, Whitelock H, Gaisford P, Calin A. A new approach to defining disease status in ankylosing spondylitis: the Bath Ankylosing Spondylitis Disease Activity Index. J Rheumatol 1994;21:2286-91.

13. Schoels MM, Aletaha D, Alasti F, Smolen JS. Disease activity in psoriatic arthritis (PsA): defining remission and treatment success using the DAPSA score. Ann Rheum Dis 2016;75:811-8.

14. Feldman SR, Fleischer AB Jr, Reboussin DM, Rapp SR, Exum ML, Clark AR, et al. The self-administered psoriasis area and severity index is valid and reliable. $\mathrm{J}$ Invest Dermatol 1996;106:183-6.

15. Calin A, Garrett S, Whitelock H, Kennedy LG, O'Hea J, Mallorie $\mathrm{P}$, et al. A new approach to defining functional ability in ankylosing spondylitis: the development of the Bath Ankylosing Spondylitis Functional Index. J Rheumatol 1994;21:2281-5.

16. Jenkinson TR, Mallorie PA, Whitelock HC, Kennedy LG, Garrett SL, Calin A. Defining spinal mobility in ankylosing spondylitis (AS). The Bath AS Metrology Index. J Rheumatol 1994;21:1694-8.

17. Bruce B, Fries JF. The Health Assessment Questionnaire (HAQ). Clin Exp Rheumatol 2005;23:S14-8.

18. McKenna SP, Doward LC, Whalley D, Tennant A, Emery P, Veale DJ. Development of the PsAQoL: a quality of life instrument specific to psoriatic arthritis. Ann Rheum Dis 2004;63:162-9.

19. Leung YY, Ho KW, Zhu TY, Tam LS, Kun EW, Li EK. Testing scaling assumptions, reliability and validity of medical outcomes study short-form 36 health survey in psoriatic arthritis. Rheumatology 2010;49:1495-501. 
20. Saad AA, Ashcroft DM, Watson KD, Symmons DP, Noyce PR, Hyrich KL, et al. Improvements in quality of life and functional status in patients with psoriatic arthritis receiving anti-tumor necrosis factor therapies. Arthritis Care Res 2010;62:345-53.

21. Tymms K, Kelly A, Bird P, Griffiths H, de Jager J, Littlejohn G, et al. Psoriatic arthritis treatment regimens, therapy duration and reasons for cessation in the biologics era: a multi-centre Australian study. Int $\mathrm{J}$ Rheum Dis 2018;21:510-6.

22. Polachek A, Al-Johani R, Li S, Ye JY, Chandran V, Gladman D. Late onset psoriatic arthritis in a longitudinal cohort: Disease presentation, activity over time and prognosis. Semin Arthritis Rheum 2019;48:834-9.

23. Sørensen J, Hetland ML. Diagnostic delay in patients with rheumatoid arthritis, psoriatic arthritis and ankylosing spondylitis: results from the Danish nationwide DANBIO registry. Ann Rheum Dis 2015;74:e12.

24. Aletaha D, Alasti F, Smolen JS. Disease activity states of the DAPSA, a psoriatic arthritis specific instrument, are valid against functional status and structural progression. Ann Rheum Dis 2017;76:418-21.

25. Lubrano E, De Socio A, Perrotta FM. Comparison of Composite Indices Tailored for Psoriatic Arthritis Treated with csDMARD and bDMARD: A Crosssectional Analysis of a Longitudinal Cohort. J Rheumatol 2017;44:1159-64.

26. Mease PJ, Accortt NA, Rebello S, Etzel CJ, Harrison RW, Aras GA, et al. Persistence of tumor necrosis factor inhibitor or conventional synthetic disease-modifying antirheumatic drug monotherapy or combination therapy in psoriatic arthritis in a real-world setting. Rheumatol Int 2019;39:1547-58.

27. Lu C, Wallace BI, Waljee AK, Fu W, Zhang Q, Liu Y. Comparative efficacy and safety of targeted DMARDs for active psoriatic arthritis during induction therapy: A systematic review and network meta-analysis. Semin Arthritis Rheum 2019;49:381-8.

28. Tan AL, McGonagle D. Psoriatic arthritis: correlation between imaging and pathology. Joint Bone Spine 2010;77:206-11.

29. Polachek A, Li S, Chandran V, Gladman DD. Clinical Enthesitis in a Prospective Longitudinal Psoriatic Arthritis Cohort: Incidence, Prevalence, Characteristics, and Outcome. Arthritis Care Res 2017;69:1685-91.

30. Pontifex EK, Dissanayake K, Bursill D, Gill T. Prevalence of minimal disease activity in Australian patients with Psoriatic Arthritis: Assessing the outcome of national funding criteria for biologic disease-modifying antirheumatic drug prescribing. Int $\mathrm{J}$ Rheum Dis 2019;22:262-8.

31. Sakkas LI, Alexiou I, Simopoulou T, Vlychou M. Enthesitis in psoriatic arthritis. Semin Arthritis Rheum 2013;43:325-34.

32. Coates LC, Kavanaugh A, Mease PJ, Soriano ER, Laura Acosta-Felquer M, Armstrong AW, et al. Group for Research and Assessment of Psoriasis and Psoriatic Arthritis 2015 Treatment
Recommendations for Psoriatic Arthritis. Arthritis Rheumatol 2016;68:1060-71.

33. Dongze W, Wong PC, Griffith JF, Tam L-S. FRI0464 Effect of biologics on enthesitis and dactylitis in patients with psoriatic arthritis: a systematic review and metaanalysis. Ann Rheum Dis 2019;78(Suppl 2):926-7.

34. Silvagni E, Bortoluzzi A, Ciancio G, Govoni M. Biological and synthetic target DMARDs in psoriatic arthritis. Pharmacol Res 2019;149:104473.

35. Tälli S, Etcheto A, Fautrel B, Balanescu A, Braun J, Cañete JD, et al. Patient global assessment in psoriatic arthritis - what does it mean? An analysis of 223 patients from the Psoriatic arthritis impact of disease (PsAID) study. Joint Bone Spine 2016;83:335-40.

36. Queiro R, Cañete JD, Montilla C, Abad M, Montoro M, Gómez S, et al. Minimal disease activity and impact of disease in psoriatic arthritis: a Spanish cross-sectional multicenter study. Arthritis Res Ther 2017;19:72.

37. Fagerli KM, Lie E, van der Heijde D, Heiberg MS, Lexberg AS, Rødevand E, et al. The role of methotrexate co-medication in TNF-inhibitor treatment in patients with psoriatic arthritis: results from 440 patients included in the NOR-DMARD study. Ann Rheum Dis 2014;73:132-7.

38. Lee S, Mendelsohn A, Sarnes E. The burden of psoriatic arthritis: a literature review from a global health systems perspective. P T 2010;35:680-9.

39. Gottlieb A, Gratacos J, Dikranian A, van Tubergen A, Fallon L, Emir B, et al. Treatment patterns, unmet need, and impact on patient-reported outcomes of psoriatic arthritis in the United States and Europe. Rheumatol Int 2019;39:121-30.

40. Heiberg MS, Kaufmann C, Rødevand E, Mikkelsen K, Koldingsnes W, Mowinckel $\mathrm{P}$, et al. The comparative effectiveness of anti-TNF therapy and methotrexate in patients with psoriatic arthritis: 6 month results from a longitudinal, observational, multicentre study. Ann Rheum Dis 2007;66:1038-42.

41. Rosen CF, Mussani F, Chandran V, Eder L, Thavaneswaran A, Gladman DD. Patients with psoriatic arthritis have worse quality of life than those with psoriasis alone. Rheumatology 2012;51:571-6.

42. Ozcan E, Yilmaz O, Tutoglu A, Bodur H. Validity and reliability of the Turkish version of the Health Assessment Questionnaire for the Spondyloarthropathies. Rheumatol Int 2012;32:1563-8.

43. Wohl Y, Reitblat O, Lerman TT, Cohen O, Reitblat T. Psychologic Morbidity Among Psoriatic Arthritis Patients in Remission or With Low Disease Activity: A Comparison Between Biologic and Conventional Synthetic Disease-Modifying Antirheumatic Drugs. J Clin Rheumatol. 2019. [Epub ahead of print]

44. Tillett W, Shaddick G, Jobling A, Askari A, Cooper A, Creamer $\mathrm{P}$, et al. Effect of anti-TNF and conventional synthetic disease-modifying anti-rheumatic drug treatment on work disability and clinical outcome in a multicentre observational cohort study of psoriatic arthritis. Rheumatology 2017;56:603-12. 